\title{
'I will be "fighting" even more for pupils with SEN': SENCOs' role predictions in the changing English policy context
}

Sue Pearson, Rafael Mitchell, Maria Rapti

\begin{abstract}
The Coalition Government's 'Green Paper' (DfE 2011) proposes a systemic overhaul of services for pupils with special educational needs in England, with increased parental choice of provision and 'sharper accountability' (p. 67) in schools. Deadlines for various stages of this reform have not been met, and its final nature remains uncertain. This paper reveals SENCOs' insights into their changing role in this turbulent policy context. This is achieved through the thematic analysis of 227 responses to an 'open-ended' question in the national Special Educational Needs Coordinator (SENCO) Survey 2012. Findings from this sample indicate that SENCOs predict that schools in England will become more inclusive, with greater shared responsibility for achievement for all, and SENCOs' increased involvement in staff training and other whole school capacity-building activities. Respondents predict a greater partnership with parents, for whom they will provide advice and links to other services. They foresee their reduced involvement in direct teaching and an intensification of their work in other ways, especially in terms of paperwork associated with pupil tracking and other accountability measures. These changes are anticipated against a backdrop of resource cuts, requiring SENCOs to show increasing self-reliance and imagination.
\end{abstract}

\section{Key words:}

accountability, inclusion, leadership, management, parental involvement, policy, SENCO

\section{Introduction}

This article draws from a national survey of SENCOs in England conducted by the University of Leeds with the support of nasen in Autumn 2012 (henceforth SENCO Survey 2012). As a re-issue of a previous survey undertaken five years previously (see Pearson, 2008a), SENCO Survey 2012 is an opportunity to understand the changing nature of the recruitment, induction and retention of SENCOs, and roleholders' attitudes to, and experiences of, organisational and national policy contexts. A report of the data is published elsewhere (Pearson \& Mitchell, 2013), and this current article focuses on a single aspect of our investigation: SENCOs' insights into the future direction of their role in a changing policy context.

This article begins with an overview of research into the role of SENCOs conducted in the last decade, followed by an account of the Coalition Government's proposed changes to SEN provision in England. An account of data collection and analysis is followed by our findings, which offer a thematic presentation of SENCOs' predictions. 


\section{Previous research into the role of SENCOs}

A dominant theme in SENCO research in the past decade has been the extent to which the role is concerned with aspects of leadership and management (e.g. Cole, 2005; Layton, 2005; Rosen-Webb, 2011; Tissot, 2013). For any productive contribution to this discussion, it is necessary to distinguish positional leadership (e.g. membership of a school's senior leadership team (SLT)), from managerial responsibilities, and relational leadership, as may be demonstrated by any and all members of a school community (MacBeath \& Dempster, 2009). The requirements of positional leadership in an organisational context can be interpreted as "a higher order set of abilities such as goal-setting, visioning, and motivating" (Dimmock, 2002: 33), whereas managerial responsibilities are deemed to be "a lower order group of activities concerned with the maintenance of performance through supervision, coordination, and control" (ibid.). Relational leadership, in an educational context, is "concerned with productive social and socializing relationships where the approach is not so much about controlling relationships through job descriptions or team processes but is about how the agent [i.e. the leader] is connected with others in their own and other's learning" (Gunter, 2006: 263).

By these criteria, the SEN Code of Practice (DfES, 2001 - henceforth CoP 2001) is very much aligned with managerial responsibilities or coordinating, supervising and overseeing. CoP 2001 states that the role of SENCO "may include:

- Overseeing the day-to-day operation of the school's SEN policy

- Coordinating provision for children with SEN

- Liaising with and advising fellow teachers

- Managing learning support assistants

- Overseeing the records of all children with SEN

- Liaising with parents of children with SEN

- Contributing to the in-service training of staff

- Liaising with external agencies including the LEA's support and educational psychology services, health and social services, and voluntary bodies" (p. 50)

As the conditional 'may' indicates, such "government guidance provides global scope, without giving much detail or being overly prescriptive" (Tissot, 2013: 34). Research since CoP 2001 has shown wide variation in the interpretation and enactment of the SENCO role, with "a high degree of local interpretation at school level' (Pearson \& Ralph, 2007: 38) as a result of both strategic decisions at the whole school level (Blandford, 2013) and the disposition of individual role-holders (Kearns, 2005).

A recommendation was made by the House of Commons' Education and Skills Select Committee (HCESSC, 2006) that the SENCO be a member of SLT-an indication of the perceived importance of formal leadership and managerial status. 
However, this was not made a statutory requirement, and the desirability of this recommendation has been a matter of recurrent debate (e.g. Morewood, 2008; Oldham \& Radford, 2011; Tissot, 2013). While this particular recommendation was not enacted, subsequent legislation has indicated a definite trend towards an increasing formalisation of SENCOs' leadership responsibilities (Rosen-Webb, 2011). For example, regulations drafted in 2008 (DCSF, 2008) required that all newly-appointed SENCOs undertake the National Award for SEN Coordination (NASENCO) which emphasises the SENCO's role in promoting inclusion across the school. For the achievement of this award, SENCOs are required to demonstrate their ability to:

"work with senior colleagues and governors to advise on and influence the strategic development of an inclusive ethos, policies, priorities and practices...[and] take a leadership role in promoting a whole school culture of best practice in teaching and learning in relation to pupils with SEN and/or disabilities" (TDA, 2009: 2-4).

This quotation contains some conceptual ambiguity: SENCOs are responsible for influencing organisational culture, practice and policies, and promoting school-wide inclusion - which suggests aspects of both positional and relational leadership; yet their role is that of advisor, a specialist who may be called upon to advise more senior colleagues. The motivation for spreading responsibility in this way may be read as a matter of principle (e.g. MacBeath \& Dempster, 2009) or pragmatism, "to ease the burden of over-worked headteachers" (Hartley, 2010: 271). Either way, it has been argued that the emphasis on SENCOs' role in promoting whole school inclusion, over their specialist knowledge of SEN-related issues, has "contribute[d] both to clarifying and to muddying the role of the SENCo" (Rosen-Webb, 2011: 160).

Oldham and Radford (2011) question whether the SENCO role should be universal or specialist, thereby highlighting the tension between the SENCO as a 'change agent' for whole school inclusion (Hallett \& Hallett, 2010), and the SENCO as SENspecialist, using advanced knowledge and skills to promote the learning of specific students. Norwich (2010) offers a model for these alternative roles (see Figure 1); (A) reflects a specialist or 'expert' positioning of the SENCO, while the (B) profile emphasises a more generic management role. 


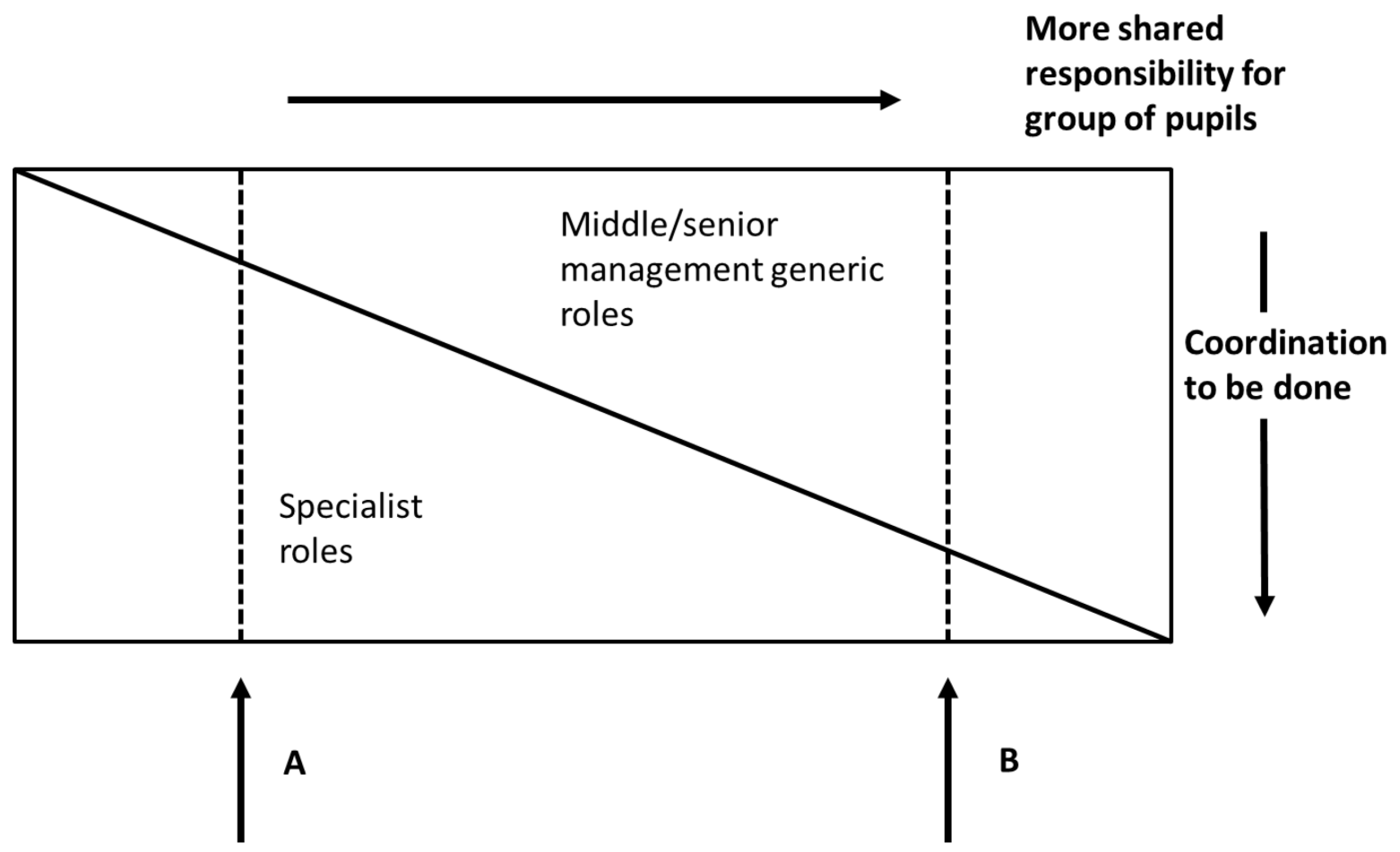

Figure 1. The balance between SENCO as a specialist and a management role (Adapted from Norwich, 2010: 43)

Hallett and Hallett (2010) interpret legislation of the former government as putting the SENCO at "the centre of the school development process" (p. 33), charging the roleholder with responsibility for 'strategic management' (consistent with the visioning and goal-setting of leadership) and 'process management' (consistent with the 'lower order' functions of coordination and supervision). Recent research has found the latter function to predominate. For example, Pearson (2008b) finds that the most common areas for which SENCOs take sole responsible are managing and timetabling TAs, managing the allocation of SEN resources, writing and reviewing SEN policy, managing students' transition to specialist provision, and bidding for funds. These reflect process management responsibilities consistent with $2001 \mathrm{CoP}$ (see above), but not strategic management or leadership. More recently, Tissot (2013) investigates the role through a survey of 146 NASENCO candidates and follow-up interviews with ten SENCOs. She finds that $48 \%$ "do not have the formal authority to lead" (p. 37), and that many are frustrated with low-level paperwork. The extent to which other members of the school community perceive SENCOs as leaders is investigated by Layton (2005) whose small-scale study, including data from NASENCO graduates and their colleagues, finds that headteachers regard SENCOs as primarily concerned with administration and managing TAs. It is also notable that in Day and colleagues' (2009) large-scale national study investigating the links between pupils' attainment and leadership in school, no consideration is given to the function of SENCOs in raising pupils' educational outcomes, either at a whole school or individual level. 
An individual's interpretation and enactment of the role of SENCO_-as A or B, or somewhere in between on Norwich's model (Figure 1) -results from the complex interaction of factors at the individual- and school-level. A demonstration of this is offered with reference to two studies (Kearns, 2005; Blandford, 2013).

Individual-level factors. Investigating the professional learning of SENCOs, Kearns (2005) recognises varying approaches to the role, for which he provides a typology:

- Arbiter, developing human resources for supporting students with SEN, seeking to boost the confidence of teachers, and using a range of sources of information to facilitating their professional development.

- Rescue[r], personally supporting pupils with SEN, identifying their needs, implementing targetted programmes, and monitoring progress; developing their own knowledge and skills based on the advice of other teachers.

- Auditor, supporting teachers to meet external accountability requirements; focusing on administrative demands, data management, legalities (e.g. appeals procedures, \& seeking additional resources); and feeling empowered and supported by bureaucratic frameworks.

- Collaborator, working with groups of teachers to plan activities relating to reviewing and evaluating provision; confident in the involvement of others who are not accountable to them; and seeing themselves as responsible for encouraging the participation and confidence of colleagues.

- Expert, interested on individual pupils with specific needs, feeling that inclusive practice is a sensitive issue to be done on a case-by-case basis.

These profiles could be seen as reflecting different points on a continuum of individual/shared responsibility for inclusion (cf. Figure 1).

School-level factors. Sonia Blandford (2013), the national director of Achievement for All (AfA), describes her initiative as a whole school improvement programme with a specific focus on raising the attainment and broader educational outcomes of students with special educational needs and disabilities (SEND) while increasing parental engagement in the school. Exploring the impact of AfA on leadership practices within 44 schools in 10 local authorities, she finds that SENCOs take on varying roles in relation to this project. In one school, AfA was led by a new appointee without a SEND background, in another school the initiative was led by a SENCO, with teachers taking responsibility for students' progress monitoring, and a parental support adviser was appointed to liaise with parents; while a third school removed the responsibility for students with SEND from the SENCO (p. 53). As can be seen, the positioning of SENCOs in these pilot projects reflects school-level decisions relating to contextual needs. 
In the last three years the Coalition Government has made ongoing interventions into current and future provision SEN provision, chief amongst which is the publication of the 'Green Paper' (DfE, 2011), the establishment of 20 'pathfinders' across the country, piloting different elements of the proposed reforms, and the promise of a new CoP for SEN (currently in its draft stage (DfE, 2013)).

The Green Paper presents an education system which offers "disproportionately poor" (p. 4) opportunities for young people with SEND, whose parents find the system to be "bureaucratic, bewildering and adversarial" (p. 4). The paper's authors are guided by a vision:

"We want to put in place a radically different system to support better life outcomes for young people, give parents confidence by giving them more control, and transfer power to professionals on the front line and to local communities" (p. 16).

This vision suggests both means and ends. The ends are improved "life outcomes" for young people and increased parent confidence, which is sought through the means of systemic reform and decentralisation of power and responsibility to the public and voluntary sectors. The values in this vision are clear, and the only notion which may need unpicking is "life outcomes", which—although it is not specified in the paper-appears to refer to a combination of measurable educational, health and employment outcomes. The key concepts underpinning this vision of reform are marketisation, performativity and decentralisation.

The remit of the Green Paper is system-wide, extending beyond implications for SENCOs. Table 1 lists the Green Paper's key proposals by chapter. The document contains few references to SENCOs, although the implementation of its proposals would entail significant changes to the expectations, practices and experiences of those enacting this role.

Table 1. Overview of proposed changes contained in the Green Paper (2011)

\begin{tabular}{|c|c|c|}
\hline Chapter & \multicolumn{1}{c|}{ Proposed changes } \\
\hline $\begin{array}{c}\text { Early } \\
\text { intervention } \\
\text { and } \\
\text { assessment }\end{array}$ & $\begin{array}{l}\text { - } \text { Quick, early identification by health professionals } \\
\text { - A single 'Education, Health and Care Plan' (EHCP) to replace } \\
\text { siving } \\
\text { parents } \\
\text { control }\end{array}$ & $\begin{array}{l}\text { - } \text { Local authorities (LAs) and schools publish a clear local offer } \\
\text { - Personal budgets given to parents }\end{array}$ \\
\hline $\begin{array}{c}\text { Learning } \\
\text { and } \\
\text { achieving }\end{array}$ & $\begin{array}{l}\text { - Parents decide between special, mainstream or a special unit } \\
\text { attached to a mainstream school }\end{array}$ \\
\hline
\end{tabular}




\begin{tabular}{|c|c|}
\hline & 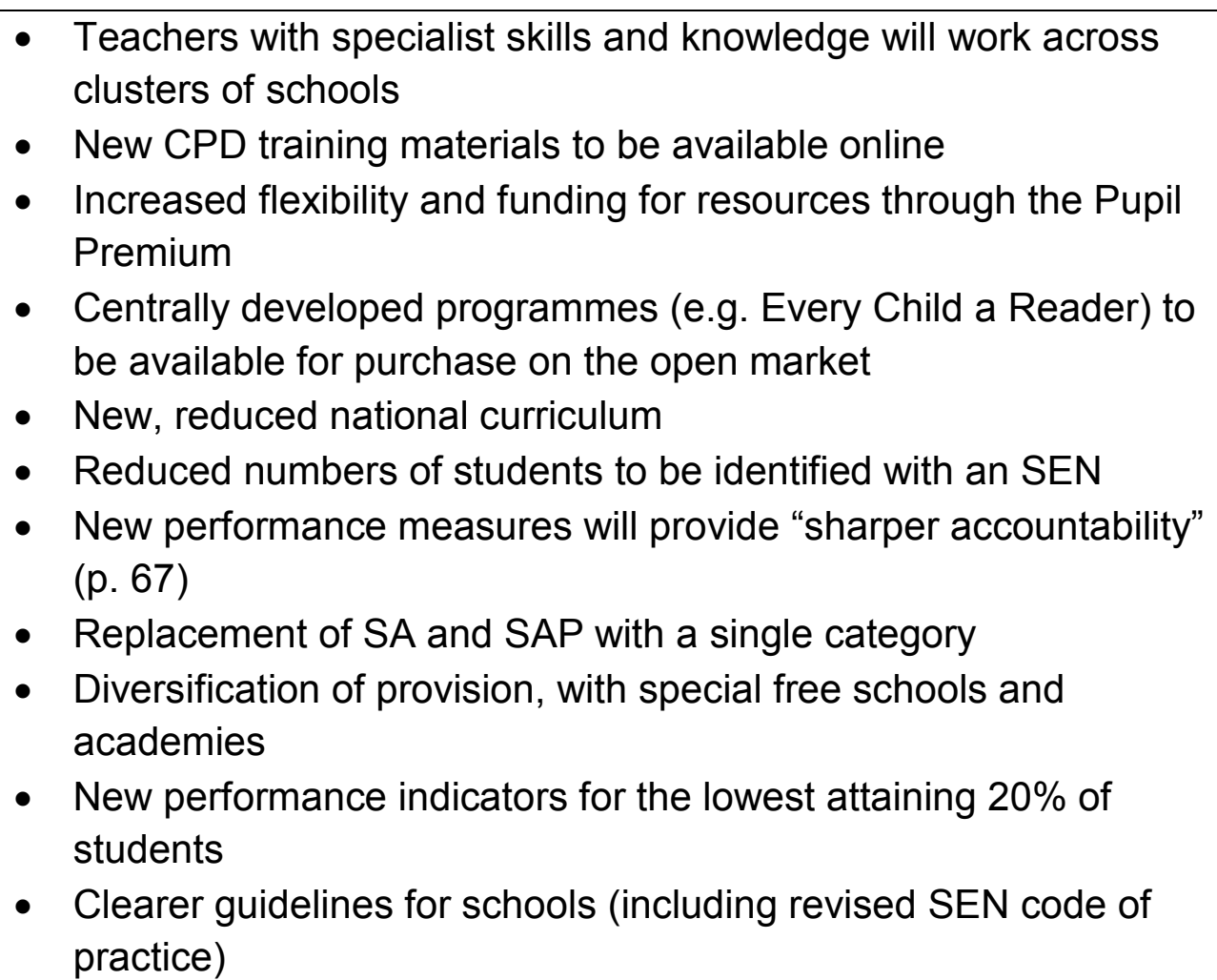 \\
\hline $\begin{array}{l}\text { Preparing } \\
\text { for } \\
\text { adulthood }\end{array}$ & $\begin{array}{l}\text { - Improved vocational education and work-related learning } \\
\text { options }\end{array}$ \\
\hline $\begin{array}{l}\text { Services } \\
\text { working } \\
\text { together }\end{array}$ & $\begin{array}{l}\text { - Local authorities will work strategically, championing the needs } \\
\text { of young people with SEND } \\
\text { - } \text { Reduced bureaucratic burdens through simplified statutory } \\
\text { guidance } \\
\text { - } \text { Removal of the recommendation for schools to use IEPs } \\
\text { - Increased innovation and collaboration between services } \\
\text { - Use of the voluntary sector to provide specialist guidance on } \\
\text { SEND as well as direct services }\end{array}$ \\
\hline
\end{tabular}

(Adapted from DfE, 2011)

Leaving aside the fine details of these proposals (which are yet to be finalised), the direction of reform is clear, and ideologically consistent with the vision outlined above; improved learning outcomes are to be achieved through the drivers of marketisation (e.g. increased parental choice), performativity (e.g. 'sharper accountability'), and decentralisation. If the Green Paper is 'ideologically consistent', this is not to deny several prominent contradictions in these proposals, not least the decentralising push of 'under-performing schools' away from local authority (LA) control, and the concurrent requirement that LAs strategically champion the needs of young people with SEND.

Different commentators have offered their interpretations of the Green Paper and its possible implications for SENCOs and the learners they support. Morewood (2012) 
laments the shift in language from 'every child matters' to 'achieving more', where achievement is conceived solely in terms of literacy and numeracy progression, rather than holistic development including aspects of health, wellbeing and participation. Robertson (2012) observes that:

"the proposals are skewed sharply towards the minority of children with special educational needs and disabilities...who have Statements [of SEN] $(2.8 \%)$ rather than the $17.8 \%$... of pupils with special educational needs and disabilities who do not have a Statement" (p. 79).

Indeed, one possible reading of the Green Paper-which proposes the replacement of Statements with Education, Health and Care Plans (EHCPs) assessed by health professionals, the collapse of in-school intervention categories (School Action (SA) and School Action Plus (SAP)), and a commitment to reducing the identification of students with SEN in schools-is that $17.8 \%$ of the school population are being redefined, or rhetorically excised from existence. The recent draft SEN CoP (DfE, 2013), however, refers to both "individual children with SEN and those who have [EHCPs]" (p. 44, our italics), suggesting an interpretation of SEN which extends beyond issues of health.

Having presented an overview of the academic debates surrounding the role of SENCOs and the changing policy context, this current paper uses SENCO Survey 2012 to 'give voice' to SENCOs working with young people across the country who are best-placed to comment on the effects of national policies in schools.

\section{Methodology}

SENCO Survey 2012 was a re-issue of a previous survey seeking to gather quantitative and qualitative data on the recruitment, induction and retention of SENCOs (for fuller details, see Pearson, 2008a). In collaboration with nasen, and using their email database, we sent links to a Bristol Online Survey to 2929 email addresses of SENCOs, of which 154 'bounced', and the assumption is that 2775 were actually received. We received 326 responses, which is a return rate of $11.7 \%$.

Many SENCOs gave the name and location of their school, which indicates that this was a national survey. Responses came from the full range of school phases: Reception (37.7\%); Primary (63.1\%); Middle (0.4\%); Secondary (34.3\%); Post-16 (11.3\%). Respondents' period of service ranged from 24 years to 8 weeks. The average length of experience was 4.8 years. $3 \%$ of respondents did not identify any additional responsibilities beyond the role of SENCO; the remainder did, and many reported multiple responsibilities. In total, 86 different additional responsibilities were identified. The most frequently-mentioned of these are set out in Table 2.

Table 1. Additional responsibilities $(n=284)$

$$
\begin{array}{|l|l|}
\hline \text { Responsibility } & \text { Number of responses } \\
\hline
\end{array}
$$




\begin{tabular}{|c|c|}
\hline Teaching & 42 \\
\hline Looked-after children & 37 \\
\hline Inclusion & 33 \\
\hline English as an additional language & 31 \\
\hline Designated child protection officer & 28 \\
\hline Senior leadership/management team & 28 \\
\hline Gifted and talented & 27 \\
\hline Deputy/assistant head & 26 \\
\hline Behaviour & 15 \\
\hline Student/NQT mentor & 15 \\
\hline
\end{tabular}

Additional responsibility for assessment, line-managing teaching assistants, safeguarding and pastoral support were also mentioned.

The survey also looked to the future, capturing SENCOs' predictions about changes to their role. This article draws from responses to an open-ended question:

- "Thinking about the role of SENCO in your school, how do you foresee it changing in the short ( 1 - 5 years) term?"

Of the 326 survey responses, 35 respondents left this question blank. The remaining 291 responses were systematically analysed according to the precepts of thematic analysis (Bryman, 2012). A first sweep of the data by one co-author revealed that 28 responses did not address the question; 17 felt there would be no changes in the role; and 19 expressed an inability to predict future changes to the role. The coding of the remaining 227 responses was both 'theory-driven' and 'data-driven' (Braun \& Clarke, 2006: 88). Specifically, coding was conducted according to the 5 a priori themes identified in the Green Paper. One theme-Preparing for adulthood—was empty, while themes referring to Resource cuts and Intensification emerged from the data.

Particular attention was given to the reliability of the coding (Cohen et al., 2011), which was addressed through intercoder agreement checks (Creswell, 2013). In addition to the coding conducted by one of the co-authors, a second co-author independently read through and re-coded the data, using the aforementioned themes. The team met and compared $20 \%$ of the data coding, exploring discrepancies. After discussion the authors agreed on the themes' names and definitions, and all responses were recoded again. This enabled the finalisation of the codebook, which includes all six themes and the responses assigned to each of them (Creswell, 2013). Following this, one co-author wrote a summary of each theme including integrated quotations from respondents, and another member of the team verified these against the data. The result of this rigorous analytic process is 
presented in the Findings section under the headings taken from the Green Paper and the two emergent categories.

\section{Findings}

\section{Early intervention \& assessment}

The replacement of Statements of SEN with EHCPs is viewed as heralding "huge changes", which many regard as a challenge. An anomalous response reflects the view that "more and more pupils [will be] diagnosed." The dominant view, however, is that there will be a steady reduction in the number of pupils on the SEN register.

Contrary to the Green Paper proposal that health professionals will undertake quick and early identification of needs, respondents believe that identification will continue throughout pupils' school career, requiring SENCOs' involvement in identification and assessment individually and in collaboration with other professionals:

"The introduction of the new [EHCP...] will encourage multi-agency working which will be highly beneficial however the practicalities of this remain unclear."

Respondents express the view that EHCPs will require knowledge and skills beyond SENCOs' current capacity:

"I will have to find means of accessing...information to keep me up to date...to ensure that children with SEN are receiving the right care, education and intervention they are entitled to."

The proposed removal of Statements leaves SENCOs feeling uncertain about their future role in intervention and assessment. As one respondent puts it, "I am not sure what role I will have in the statement process."

\section{Giving parents control}

Respondents indicate general ways in which legislation in this area will impact on their role, for example, the "need to have excellent relationships with parents." Increased work with parents is understood to require an investment of time.

While some foresee parents having "greater control of funds for SEN", this issue is not generally framed as a 'control' issue, and is often presented as a partnership which needs to be developed:

"Parents should...be supported and encouraged to be involved with all aspects of their children's learning journey." 
"[SENCO] is becoming a facilitator role - in terms of...support[ing and] empowering parents - giving them the opportunity to take a more informed role."

SENCOs envisage a greater role for themselves in advising parents, particularly in relation to the budget. For some, the re-positioning of parents as budget-holders is regarded as a professional challenge:

"I am concerned about how to meaningfully involve parents in a manageable way."

"[l]t may become more difficult trying to accommodate parental expectations with funding issues."

For a minority, parental involvement in budgeting is seen solely in negative terms ("very worrying"), and associated with an overall reduction of funding to schools, rather than a re-direction of funds. In particular, SENCOs are concerned that a reduction in funding lead to staffing cuts.

\section{Learning and achieving}

As indicated in Table 1, this theme incorporates the concepts of inclusion and accountability - the latter advanced as a mechanism for achieving the former. SENCOs have a positive vision of schools becoming more inclusive, with "[l]ess emphasis on SEN, more achievement for all." While schools will cater for pupils whose needs are "increasingly complex", respondents predict "much clearer thoughts on whether they should be on [the] register or covered within differentiation." Respondents foresee SENCOs as demonstrating:

"Increasing whole school leadership focussing on underachieving pupils and those with SEND."

SENCOs anticipate taking a lead role in making schools more inclusive for all-not just for pupils with SEN, since the responsibility for ensuring AfA is viewed as the responsibility of all staff members.

Respondents foresee SENCOs moving from the periphery to the heart of school processes, offering vision, strategy and instructional leadership. They will champion an inclusive agenda, empowering others in the school community

"to become more proactive rather than reactive [with,] greater input into class teaching rather than specialist group work."

The job will become "less of a paperwork [and more of] a leadership role, enabling more staff to take on responsibilities [for inclusion]." A necessary condition for this is whole school capacity building, for which SENCOs will coordinate and deliver 
professional development support for teachers and support staff. A range of means are suggested for individual and organisational capacity building, including professional consultancy, workshops, coaching, and lesson observation and feedback.

A reduction in SENCOs' involvement in teaching is predicted, partly because mainstream lessons will be more inclusive, and partly because of the changing responsibilities of the post. One respondent wonders "Could this default to a non teaching role?" Another points out that the "feasibility of SENCo/Inclusion lead also carrying a teaching commitment does not seem possible." One area of increasing responsibility is financial management, and the expectation that SENCOs will be responsible for all aspects provision, costing and buying-in services, coordinating interventions, and monitoring effectiveness. Their role will become increasingly "data driven", tracking pupils' progress and calculating the effectiveness of interventions. This is presented solely in terms of external accountability (e.g. to Ofsted) rather than internal accountability to the school community. One respondent suggests that, the intensification of the job, the reduction in funding, and increased pressure to meet external accountability requirements is like "being held accountable for the progress of SEN pupils with one's arms tied behind one's back." Another warns that the role is becoming

"so much concerned with outcomes that can be measured in hard data, that we are in danger of losing sight of children with SEN as individuals."

\section{Services working together}

SENCOs see their future role within "more of a multi-agency approach":

"with the changing emphasis on the single plan, there will be a lot more coordination of services required...[for this] to be effective."

Respondents foresee the SENCO occupying a mediating role, "linking outside agencies to parents", and "working with other agencies, possibly having a 'keyworker' role", such as taking a lead practitioner role for the Common Assessment Framework (CAF).

A reduction in external support will require that schools be more self-reliant, and that SENCOs build their knowledge and skills to support the broad continuum of learner needs:

"I foresee a greater need for expertise around specific learning needs as other services are withdrawn or restricted."

To this end, respondents predict that SENCOs will make increasing use of professional networks and knowledge-sharing within and between schools. 
They predict increasing responsibility for 'buying in' services (such as educational psychologists), and trying to enlist support from other sources, including the voluntary sector.

\section{Resource cuts}

$15 \%$ of respondents predict an overall reduction in the resources available to support students with SEN, either because there will be "less funding and less staff", or because

"every year [there is] a significant increase in SEN pupils, especially those with more severe and more complex needs...We are expected to provide for all their needs and TA support with the same staffing and funding we've had previously."

This situation is compounded by a reduction in support from LAs, requiring that schools pay for services which they previously received for free. This is predicted to negatively impact upon schools' abilities to meet pupils' needs:

"reduced funding will make [things] more difficult and force [the school] into a methodology that may not be efficient for those pupils to make progress."

One respondent explains that SENCOs will have to be "more imaginative" to overcome this challenge.

\section{Intensification}

$33 \%$ of SENCOs predict an intensification in their role: they will be "taking on more as the Green paper rolls out" and support from LAs is reduced. They foresee a general increase in bureaucracy, especially in relation to accountability data, and predict "more paperwork for less impact." In contrast, two respondents shared the view of the Green Paper that there will be an overall reduction in bureaucracy.

\section{Discussion}

While this study indicates uncertainty about concrete aspects of future policy, particularly in relation to EHCPs and who will be on the SEN register, there is a surprising amount of agreement regarding certain aspects of the role and trends affecting the organisational context (see Table 3).

Table 3. Overview of predicted changes for schools and SENCOs 


\begin{tabular}{|c|c|}
\hline $\begin{array}{c}\text { More inclusive schools } \\
\text { Achievement for All, inclusive } \\
\text { pedagogies (e.g. Quality First } \\
\text { Teaching), collective responsibility for } \\
\text { SEN }\end{array}$ & $\begin{array}{l}\text { - Providing vision for inclusion } \\
\text { - Supporting professional } \\
\text { development across the school } \\
\text { - Less direct teaching } \\
\text { - Costing and coordinating } \\
\text { interventions }\end{array}$ \\
\hline $\begin{array}{l}\text { "Sharper accountability" } \\
\text { Increasing responsibility for pupil } \\
\text { progress on narrowly-defined } \\
\text { performance measures }\end{array}$ & $\begin{array}{c}\text { - Role is more "data driven" } \\
\text { - Responsibility for tracking pupils' } \\
\text { progress } \\
\text { - Increased paperwork }\end{array}$ \\
\hline $\begin{array}{l}\text { Increased parental involvement } \\
\text { Parental input on funding decisions }\end{array}$ & $\begin{array}{l}\text { - Developing relations with parents } \\
\text { - Informing and advising parents } \\
\text { - Increased time commitment }\end{array}$ \\
\hline $\begin{array}{c}\text { Reduced resources } \\
\text { LA cuts, reduced funding for schools, } \\
\text { more pupils with "complex needs", } \\
\text { more self-reliant }\end{array}$ & $\begin{array}{l}\text { - More expertise needed, using } \\
\text { networks for knowledge/skill sharing } \\
\text { - Seeking support from } \\
\text { external/voluntary sector } \\
\text { - Intensification of role as resources } \\
\text { are spread thinner }\end{array}$ \\
\hline
\end{tabular}

The SENCOs in this sample have a vision of inclusive schools, in which there is a collective responsibility for the achievement of all learners. They see themselves as taking an instructional leadership role for organisational capacity building, advising, training and coaching colleagues. The view expressed by these SENCOs is consistent with the Green Paper's proposals, and also-significantly—with CoP 2001, which states that SENCOs may have responsibility for "advising fellow teachers...[and] contributing to the in-service training of staff" (DfES, 2001: 50). Since our data relate to SENCOs' predictions of changes to their role over the next 1 -5 years, two interpretations are suggested: either these aspects of CoP 2001 are not yet established elements of practice for the SENCOs in this sample, or the respondents foresee further developments in their professional capacity-building role. In support of the latter interpretation, SENCOs discussed increasing responsibility for staff development-suggesting that this was an aspect of their current practice. By developing colleagues and fostering school-wide use of inclusive pedagogies, SENCOs will vicariously support pupils' learning. Indeed, as these associated responsibilities occupy a larger share of SENCOs' time, our respondents predict a reduction or curtailing of direct teaching responsibilities. This would constitute a significant shift in practice, since teaching is currently the most-reported additional responsibility of SENCOs (see Table 2).

While the Green Paper links sharper accountability with improving pupils' learning, there is no evidence that these SENCOs make such a connection. They do see their 
work as becoming increasingly focused on monitoring pupil progress data and the impact of interventions, however, this is regarded as "more paperwork for less impact." To put it another way, SENCOs do not feel that the constant generation and monitoring of 'pupil data' will lead to improvements in pupils' learning, or that such internal surveillance is a productive use of time. This aspect of SENCOs' work seems to have undergone a significant transition in the last 12 years: CoP 2001 states - rather modestly — that SENCOs may be involved in "Overseeing the records of all children with SEN" (DfES, 2001: 50); and in the intervening years-driven by the performativity agenda, with ever-increasing pressure on schools to generate 'data' to evidence 'value added'-a vast amount of time, energy and other resources have been diverted away from teaching towards data-gathering. It is interesting, then, that these SENCOs do not associate this effort with improved pupil learning or provision-as they do with the collegial development of inclusive pedagogies.

Greater parental involvement in schooling is predicted, and many respondents welcome this. SENCOs in this sample indicate that they anticipate working in partnership with parents, liaising between parents and other service providers, offering information and advice, and facilitating parents' meaningful involvement in decisions. They clearly predict an advance on the responsibilities posited by CoP 2001 ("Liaising with parents" - DfES, 2001: 50), although the exact nature of parental involvement and the means of achieving this remain unclear. Respondents also raise the issue of parents' personal budgets, and are concerned about how this may affect staffing, but there is no agreement on the nature or extent of parents' influence on budgeting within the school, and whether this is conceived as consultation, participation in decision-making, or oversight. In the minds of some, this issue is closely related to the predicted resourcing cuts-it is seen as a withdrawal, rather than a re-direction of funds. SENCOs' predictions of increasing financial stringency are based on current experiences of cuts, and there are fears that schools will have to reduce levels of staffing, which will negatively affect the adequacy of provision. Respondents discuss the need to address these challenges with imagination, and show a remarkable degree of resilience. As LA services are cut and schools become increasingly dependent on their own resources, the SENCOs in this sample are looking outwards, meeting the challenge by using professional networks to build their own expertise.

In the last decade or so, the terms used to describe SENCOs' work have shifted from those of management (coordinating, overseeing, supervising - CoP 2001) to include those of leadership ("promoting a whole school culture of best practice in teaching and learning" - TDA, 2009: 2-4). A question we were not able to unpack was the potential influence of NASENCO and other qualifications (e.g. MA SEN) on responses in the sample, yet it seems at least possible that the high representation of NASENCO-holders ( $41 \%)$ in the sample added a bias towards the identification of future leadership responsibilities. 
While there are identifiable trends in the SENCO's role, significant uncertainties remain over fundamental issues such as which pupils will be identified as having SEN, how budgets will be allocated, and the role of the LA. Regional and betweenschool variations which already exist are being overlaid by practitioners' uncertainties about future policy, and the gap between intentions and realities. There is a pressing need for clarity in the above areas, as the more that SENCOs, schools and families understand of their freedoms and obligations, their rights and responsibilities - the greater the likelihood of pupils receiving a better deal. SENCOs are adept at working with children, families and colleagues in challenging circumstances, and they are familiar with the turbulence of policy change. The respondents in this sample show their willingness to lead inclusion in schools, but for this to be achieved, they too must be well led-and this requires an end to the current policy uncertainty. To paraphrase a line from the Green Paper (DfE, 2011: 41), the government must take the earliest opportunity to communicate a clear offer for families and schools to clarify what support is available and from whom.

\section{References}

Blandford, S. (2013) The Impact of 'Achievement for All' on School Leadership. Educational Management Administration and Leadership. 41, 45-62.

Braun, V. \& Clarke, V. (2006) Using thematic analysis in psychology. Qualitative Research in Psychology. 3, 77-101.

Bryman, A. (2012) Social research methods (4th edition). Oxford: Oxford University Press.

Cohen, L., Manion, L. \& Morrison, K. (2011) Research methods in education 7th ed. London: Routledge.

Cole, B. A. (2005) Mission impossible? Special educational needs, inclusion and the re-conceptualization of the role of the SENCO in England and Wales. European Journal of Special Needs Education. 20, 287-307.

Creswell, J. W. (2013) Qualitative inquiry \& research design: choosing among five approaches (3rd edition). London: SAGE Publications.

Day, C., Sammons, P., Hopkins, D., Harris, A., Leithwood, K., Gu, Q., Brown, E., Ahtaridou, E. \& Kington, A. (2009) The impact of school leadership on pupil outcomes: final report. London: Dept. for Children, Schools and Families.

Department for Education and Skills (DfES). (2001) Special Educational Needs Code of Practice. Annesley, Nottinghamshire: DfES Publications.

Department for Education (DfE). (2011) Support and aspiration: a new approach to special educational needs and disability. A consultation. (The 'Green Paper'). 
London, TSO. Retrieved from:

www.education.gov.uk/publications/eOrderingDownload/Green-Paper-SEN.pdf. Accessed on: 14/7/13.

Department for Education (DfE). (2013) Indicative Draft: The (0-25) Special Educational Needs Code of Practice. Retrieved from:

http://media.education.gov.uk/assets/files/pdf/s/sen\%20code $\% 20$ of $\% 20$ practice $\% 20 \mathrm{i}$ ndicative $\% 20$ draft $\% 20$ for $\% 20$ committee.pdf. Accessed on: 26/3/13.

Department for Children, Families and Schools (DCFS). (2008) The Education (Special Educational Needs Co-ordinators) (England) Regulations 2008. Retrieved from: http://www.legislation.gov.uk/uksi/2008/2945/made?view=plain. Accessed on 6/11/13.

Dimmock, C. (2002) 'Educational Leadership: Taking Account of Complex Global and Cultural Contexts', in Walker, A. \& Dimmock, C. (eds.) School Leadership and Administration: Adopting a Cultural Perspective. London: RoutledgeFalmer.

Gunter, H. (2006) Educational leadership and the challenge of diversity. Educational Management Administration \& Leadership. 34, 257.

Hallett, F. \& Hallett, G. (2010) Transforming the role of the SENCO. Maidenhead: Open University Press.

Hartley, D. (2010) Paradigms: How Far Does Research in Distributed Leadership 'Stretch'? Educational Management Administration \& Leadership. 38, 271-285.

House of Commons Education and Skills Select Committee (HCESSC). (2006) Special Educational Needs. Third report of sessions 2005-6 (Vol. 1). London: HMSO.

Kearns, H. (2005) Exploring the Experiential Learning of Special Educational Needs Coordinators. Journal of In-Service Education. 31, 131-150.

Layton, L. (2005) Special educational needs coordinators and leadership: a role too far? Support for Learning. 20, 53-60.

MacBeath, J. E. C. \& Dempster, N. (2009) Connecting leadership and learning: principles for practice. London: Routledge.

Morewood, G. D. (2008) The 21st century SENCo. SENCo Update. 100.

Morewood, G. D. (2012) Is the 'Inclusive SENCo' Still a Possibility? A Personal Perspective. Support for Learning. 27, 73-76.

Norwich, B. (2010) What implications do changing practices and concepts have for the role of the SEN coordinator? in Hallett, F. \& Hallett, G. (eds.) Transforming the Role of the SENCO, Open University Press: 37-50. 
Oldham, J. \& Radford, J. (2011) Secondary SENCo Leadership: A Universal or Specialist Role? British Journal of Special Education. 38, 126-134.

Pearson, S. (2008a) Deafened by silence or by the sound of footsteps? An investigation of the recruitment, induction and retention of special educational needs coordinators (SENCOs) in England. Journal of Research in Special Educational Needs. 8, 96-110.

Pearson, S. (2008b) The Working Lives of SENCOs. Retrieved from: http://www.nasen.org.uk/uploads/publications/70.doc. Accessed on 13/07/13.

Pearson, S. \& Mitchell, R. (2013) The recruitment, induction and retention of Special Educational Needs Co-ordinators (SENCOs). Retrieved from: http://www.nasen.org.uk/uploads/publications/269.pdf. Accessed on 05/05/13.

Pearson, S. \& Ralph, S. (2007) The identity of SENCos: insights through images. Journal of Research in Special Educational Needs. 7, 36-45.

Robertson, C. (2012) Special educational needs and disability co-ordination in a changing policy landscape: making sense of policy from a SENCo's perspective. Support for Learning. 27, 77-83.

Rosen-Webb, S. M. (2011) Nobody Tells You How to Be a SENCo. British Journal of Special Education. 38, 159-168.

Training and Development Agency (TDA). (2009) Standards for the National Award of SEN Coordination. London: Training and Development Agency for Schools.

Tissot, C. (2013) The role of SENCos as leaders. British Journal of Special Education. 40, 33-40. 